\title{
O ASSISTENTE SOCIAL NA ESCOLA CAMINHOS PARA EFETIVAÇÃO DE POLÍTICAS SOCIAIS
}

\author{
Maria José FERREIRA ${ }^{1}$ \\ Célia Maria DAVID ${ }^{2}$
}

RESUMO: A escola sendo uma porta de entrada á comunidade, ela está sujeita aos conflitos e limites gerados pelas expressões da questão social que reflete no âmbito escolar. Nessas condições, o assistente social tem muito a contribuir com a política pública de Educação e com os desafios apresentados para a superação do rendimento escolar e a formação cidadã dos alunos. Os avanços evidenciam as razões que acreditamos serem importantes para a aprendizagem dos alunos e maior adesão da família aos projetos da EMABEM, pois, somente com desenvolvimento de estratégias de participação das famílias na escola, teremos o tão sonhado sucesso escolar nas diferentes camadas sociais”. Assim, o objetivo deste trabalho é elencar práticas desenvolvidas pelas assistentes sociais junto à gestão escolar que centra suas atividades no sucesso do educando. A estruturação do trabalho do Serviço Social ocorreu através do estudo socioeconômico das famílias, em visita domiciliar, atendimento individual e grupal e acompanhamento de freqüência. A contribuição do serviço social na EMABEM é evidenciada nas ações articuladas á gestão escolar. As intervenções realizadas pelo serviço social subsidiam para soluções qualitativas no processo Ensino aprendizado e na integração do educando. O assistente social contribui com a normalização de práticas articuladas ás redes de serviços em Uberaba, que confirmam o impacto positivo no acesso e a participação das famílias na construção de uma Escola Cidadã.

PALAVRAS-CHAVE: Assistente social. Família. Aluno.

Discutir sobre o Serviço Social na educação, nos remete a repensar o campo de formação profissional e o trabalho do assistente social, tanto na esfera do mercado de trabalho quanto e na dimensão educativa. Ao longo dos anos 70 e metade dos anos 80, o mercado de trabalho passa por alteração no que se refere à atuação do assistente social no âmbito da política educacional. Numa aproximação com a alteração que envolve a atuação do assistente social no âmbito da política educacional, compartilhamos da visão de Iamamoto (2008, p.50) que define “[...] a década de 80 como período fértil na definição de rumos técnicos-academicos e políticos para o Serviço Social.”

\footnotetext{
${ }^{1}$ UNESP - Universidade Estadual Paulista. Faculdade de Ciências Humanas e Sociais - Pós-Graduação em Serviço Social. Membro do grupo de pesquisa: políticas públicas e democratização do ensino no Brasil: a implementação das propostas educacionais: mudanças e permanências. Franca - SP - Brasil. 14409-160 - zezesocial@hotmail.com

${ }^{2}$ UNESP - Universidade Estadual Paulista. Faculdade de Ciências Humanas e Sociais - Departamento de Educação, Ciências Sociais e Política Internacional. Líder do Grupo de Pesquisa - Políticas Públicas e Democratização do Ensino no Brasil: a implementação das propostas educacionais: mudanças e permanências. Editora chefe da Revista Eletrônica Camine: caminhos da educação. Franca - SP - Brasil. 14409-160 - cmdavid@hotmail.com.br
} 
Ao longo das décadas 70 e 80, houve uma grande discussão coletiva acerca da elaboração de um projeto profissional que norteasse a atuação do assistente social. $\mathrm{O}$ “Código de Ética Profissional do assistente social, de 1993, na Lei 8662/93 da regulamentação da profissão de Serviço Social e, hoje na nova proposta de diretrizes gerais para o curso de Serviço Social.” (IAMAMOTO, 2008. p.50).

O Código de Ética do profissional de Serviço Social, além da qualidade na parte teórica e político institucional, trazem um reconhecimento da Associação Brasileira de Ensino e Pesquisa em Serviço Social - ABEPSS, sendo relevante para esse profissional da assistência social.

Na década de 90, a presença do Assistente Social no espaço da educação tornase possível de atuação, e “[...] entra neste cenário como uma categoria que é de pesquisadora, reconhecida pelas agencias de fomento.” (IAMAMOTO, 2008, p.51).

A aprovação das diretrizes para o curso de Serviço Social, realizada em debate em 1996, suscitou orientações sobre a formação profissional, cuja educação é pensada como um campo da intervenção estatal e dimensão universitária. A nova lei de Diretrizes e Bases da Educação abriu espaço para o Serviço Social no campo educacional.

\section{A educação quando compreendida como Política Social publica requer uma reformulação na posição estratégica que ocupa na dinâmica da globalização e na dinâmica da atuação profissional. (ALMEIDA, 2000, p.20).}

A inserção do profissional de Serviço Social na Escola Municipal Adolfo Bezerra de Menezes (EMABEM) ${ }^{3}$ se deve às múltiplas faces de expressão da questão social emergente no cotidiano escolar, como: dificuldade socioeconômica, culturais e políticas, violência, envolvimento com drogas, alcoolismo, um acesso limitado à informação, à saúde pública, à educação, a uma moradia digna com saneamento básico, à alimentação, ao emprego e benefícios bolsa-família, benefício de prestação continuada, aposentadoria, ou seja, aos serviços assistenciais conforme a necessidade da família apresentada no atual momento.

A escola é repleta de desafios e aprovações o que requer uma intervenção estratégica e coletiva aos demais profissionais. Transformar o reconhecimento em “coletivos” é fundamental.” Nesse contexto, o assistente social pode atuar nas relações

\footnotetext{
${ }^{3}$ A escola, fundada no ano de 1959 pela Sra. Aparecida Conceição Ferreira, com a finalidade de proporcionar assistência educacional a famílias carentes do município de Uberaba-MG.
} 
sociais entre a escola, a família e a comunidade, contribuir com um ensino de qualidade e fortalecer parceiros capazes de inverter a situação apresentada no cotidiano escolar ${ }^{4}$.

O fazer profissional tem na prática seu espaço privilegiado, onde o individuo busca na teoria conhecimentos sistematizados que lhes permitem atribuir sentido a este fazer e aos seus objetivos. (NICOLAU, 2004, p. 95).

E nessa perspectiva de buscar melhorar a prática por meio do espaço intelectual, é que o assistente social estará bem preparado para inseri-la nas instituições e trabalhar conforme ao que lhe é demandado. Assim, ressaltamos que para iniciação do trabalho na EMABEM, utilizamos como procedimento a Pesquisa de campo, com 230 famílias, com o objetivo de traçar o perfil socioeconômico e conhecer os diversos aspectos da realidade que as cerca. Em seguida, realizamos uma pesquisa com alunos matriculados no $5^{\circ}$ ao $9^{\circ}$ ano do ensino fundamental, com a finalidade de traçar sua perspectiva de vida dentro do contexto em que estão inseridos.

A pesquisa foi um procedimento utilizado para dar visibilidade ao trabalho do assistente social, e elaborar praticas interventivas que contemplem a emancipação do público atendido.

\begin{abstract}
A pesquisa significa investigar sistematicamente uma situação problemática em uma dada comunidade ou em uma organização, propondo-se aos membros de um grupo participar, ativamente, da definição do problema a ser investigado. (CHIZZOTTI, 2008. p.93).
\end{abstract}

Observamos que dos 165 estudantes matriculados no $6^{\circ}$ ao $9^{\circ}$ ano na EMABEM, 68 não tem motivação quanto aos estudos e nem perspectivas de vida profissional futura. Os dados mostram que essa problemática é decorrente do próprio ambiente em que a criança está inserida, isto é, ela passa a ser movida pelo exemplo que tem em casa. A pesquisa mostra que das 230 famílias pesquisadas atendidas pela escola, 95 vivem em condições desfavoráveis em matéria de habitação precária, baixa renda, desemprego, pobreza. A pesquisa aponta também que dentre as 230 famílias 15 são analfabetas e 45 famílias semi-analfabetas. Segundo dados da pesquisa, a problemática apresentada é devido à falta de acesso a uma educação escolarizada.

${ }^{4} \mathrm{O}$ primeiro contato da EMABEM com o profissional assistente social foi por meio de duas assistentes sociais que em diferente período, realizaram um trabalho como voluntárias a unidade de ensino. A partir desse contato percebeu-se a necessidade de inserir o profissional de Serviço Social na referida escola. A parceria que o Lar da Caridade assume com a escola, viabilizou esse profissional a equipe dirigente dessa unidade. 
Notamos que essas famílias trazem na sua historia de vida, condições que foram desfavoráveis para o acesso a educação formal. Um dos complicadores é por serem oriundos do meio rural, consequentemente, interromperam os estudos na adolescência, em virtude da necessidade de contribuir com o sustento da família, ou outro à dificuldade de acesso a determinada unidade de serviço, do Município, seja educacional, de assistência social e de saúde. Quanto à organização familiar, 25 são formadas pela categoria monoparental, sendo essas famílias numerosas, compostas por mais crianças em idade escolar do que adultos sem condições de proporcionar um ambiente motivador de estudos, de leitura enfim, de novas perspectivas.

Esses não são fatores determinantes no Índice de Desenvolvimento da Educação Básica (IDB) da EMABEM, mas interfere na auto-estima dos alunos, o que por vezes, repercute no baixo rendimento escolar do educando. Se os pais não tiveram oportunidade de acesso ou motivação a uma educação escolarizada na infância, consequentemente a influência persistirá sobre o processo escolar dos filhos no atual contexto. “As condições de reprodução nas relações sociais é a continuidade do processo de produção social.” (IAMAMOTO, 2008. p.46).

Em atendimento realizado com as famílias, percebemos a dificuldade que elas trazem de superar os impasses em suas vidas. Entre os obstáculos destaca-se o fato da maioria ser monoparental, e se tiver que optar por "escola” ou trabalho, a família opta pelo trabalho por ver nele prioridade, já que é uma fonte de renda percapita, que ajuda a manter o sustento da família. Neste contexto, observamos a responsabilidade recair sobre a escola.

Atentamos para o contexto histórico da EMABEM que traz uma filosofia de educar com amor, responsabilidade e caridade arraigada no assistencialismo. Além da preocupação frente à discriminação voltada aos filhos e portadores do pênfigo, a escola foi criada com o objetivo de atender essa clientela, o que pendura até os dias atuais. A escola comovida pelos “problemas” que surgem na família atual, acaba por fortalecer na mesma, a transferência de suas responsabilidades para EMABEM.

Percebe-se a necessidade de um trabalho mais efetivo com as famílias, onde as relações família e escola se estreitam desde que cada uma reflita sobre o seu dever enquanto entidades precursoras de motivação. 
para a instrução de novas gerações. As famílias têm de dar acolhimento a seus filhos: um ambiente estável, provedor, amoroso. (SZYMANSKI, 2003, p.62).

É importante criar parcerias com serviços de saúde, educação, assistência social, habitação ONGs, OGs, fortalecer o trabalho em rede e viabilizar atendimento integral as para ajudar aquelas famílias com dificuldades, para dar condições necessárias às suas crianças. Conforme Gomes (1994, p.60):

Embora seja inegável a importância da família como grupo socializador, outras agências sociais e até mesmo alguns espaços competem com ela, diuturnamente, e vão se tornando demasiadamente fortes na sociedade atual.

É mister ressaltar, que temos consciência da importante missão que a família e a escola desempenham no processo educacional do aluno.

Presumidamente devemos investir nos alunos, viabilizar oportunidade em conhecê-los e relacioná-lo mutuamente com diversas realidades que colaboram com seu crescimento pessoal, interpessoal e intelectual. “A escola e a família preparam os membros jovens para sua inserção futura na sociedade e para o desempenho de funções que possibilitem a continuidade da vida social.” (SZYMANKI, 2003, p.61). Vale ressaltar, que temos consciência do importante papel que a família e a escola desempenham na formação do educando como futuro cidadão e reforçamos com a visão de cidadania que essa aprendizagem é por meio do exercício de ações coletivas de participação no espaço público, na conquista da autonomia e da emancipação do sujeito, consolidada em formas e critérios de participação no todo social.

É preciso destacar que 300 crianças e adolescentes, recebem atendimentos especializados nos projetos da escola: Centro Integrado de Ensino Municipal (CIEM); Projeto Jovem-Músico; Projeto Aparecida Conceição Ferreira (Vó Cida) e Projeto ComVivência e com a instituição parceria Lar da Caridade. A partir da compreensão da própria educação que recebem externamente, o usuário terá condições internas para fazer e agir de forma diferente, influenciando seu núcleo familiar e grupo escolar.

A família funciona como um sistema de interação sendo constituída por elementos ligados entre si, de forma que uma mudança em um elemento será seguida por uma nova mudança nos outros elementos. (SZYMANSKI, 2003, p.16). 
Através do trabalho interdisciplinar, a assistente social articula com diversas áreas do saber com o objetivo de criar mecanismos de intervenção que possam contribuir no processo escolar, desenvolver projetos para o resgate da auto-estima, valores, expectativa de mundo, diminuir o índice de evasão escolar com atividades técnicas e direcionadas, e facilitar acesso e permanecia na educação escolarizada e não escolarizada.

Vejamos que a atuação profissional apresenta para o trabalho em equipe uma tarefa desafiadora, onde nós profissionais participantes do processo, temos que desenvolver ações coletivas que serão caracterizadas por caminhos e experiências diferenciadas, mas com mesmo propósito. Assim, se não existir a coletividade, troca de conhecimentos, experiências e diálogos, teremos uma difícil missão para desenvolver um trabalho contínuo com qualidade.

\begin{abstract}
A participação quando existe de fato, é necessariamente educativa, pois educa e propicia nível cada vez mais elevados de consciência e organicidade que dar-se-ão ações concretas de transformação social, e, dessa maneira, consegue-se influir, direta ou indiretamente, na transformação da realidade. (GADOTTI; GUTIERREZ, 2005, p.27).
\end{abstract}

Ressalto novamente a importância do assistente social no campo escolar, pelo seu movimento de integração, que possibilitará melhoria e acessibilidade às condições da constituição do direito á educação, saúde, habitação e lazer. É nessa perspectiva que o Serviço Social junto da EMABEM, procura desenvolver ações de oportunidade aos estudantes, famílias, profissionais e comunidade, acesso à informação, conhecimento e esclarecimento, superando limites que a sociedade impõe sobre suas condições de vida. Dessa forma, podemos afirmar que:

O Campo educacional torna-se para o Assistente Social hoje não apenas um futuro campo de trabalho, mas sim um componente concreto d seu trabalho em diferentes áreas de atuação que precisa ser desvelado, visto que encerra a possibilidade de uma ampliação teórica, e instrumental da sua própria atuação profissional e de sua vinculação às lutas social que se expressam na esfera da cultura e do trabalho, centrais nessa passagem de milênio. (ALMEIDA, 2000, p.74).

No que se refere ao trabalho da assistente social junto à equipe dirigente (coordenação pedagógica e direção), em prol dos alunos e suas família, temos resultados satisfatórios se comparados com o inicio do trabalho que iniciou com numero insatisfatório quanto a participação dos pais e alunos. Hoje a escola conta com a 
participação de aproximadamente 60 pais nas reuniões escola de pais que acontece uma vez ao mês. Quanto aos alunos com idade 0 a 14 anos, contamos com 300 inseridos em projetos desenvolvidos pela escola e pelo Lar da Caridade.

Com a transformação, é pertinente que o assistente social (re) conheça as relações entre escola e família, escola e comunidade, repensar a concepção de homem e de mundo de cada sujeito, para estabelecer mediações que transmitam conhecimentos e esclarecimentos, que lhes os possibilitem arquitetar sua própria identidade sem “desfazer” dos valores que trazem.

Nesse contexto, temos leis que definem essa assistência ao conhecimento como prioridade para emancipar a pessoa dentro da sua realidade atual. Assim, recorremos ao Estatuto da Criança e do Adolescente que reforça que a educação como um direito fundamental para a criança e o adolescente, sendo reforçado pela Constituição Federal que preconizado esse direito como universal, com objetivo de proporcionar condições de vida adequada e acessibilidade aos serviços assistenciais a todos os cidadãos independentes da classe social que ocupam na sociedade.

Nessa perspectiva, a Lei ${ }^{\circ}$. 9.394, de dezembro de 1996, “[...] define as ações que devem ser realizadas e quais os objetivos a serem atingidos.” (SOUZA; SILVA, 2002). Ela vem para reforçar em termos legais, a efetivação da garantia do padrão de qualidade do ensino e igualdade de condições para o acesso e permanência do aluno na escola, por ser considerada uma instituição própria para ministrar uma educação escolar, porém, com apoio não só da equipe escolar como, também, da família e, principalmente, do Estado, como consta em leis constitucional.

SOCIAL WORKER IN THE PATHWAYS TO EFFECTIVE SCHOOL OF SOCIAL POLICY 
ABSTRACT: The school is a gateway to the community, it is subject to limits generated by conflicts and expressions of social issue that reflects in the school. Under these conditions, the social worker has much to contribute to public policy Education and the challenges presented to overcome the academic performance of students and civic education. The developments highlight the reasons that we believe are important to student learning and greater adhesion to the family of EMABEM projects. We agree with Van Zant (1988, p. 195) when he states that "only by developing strategies of families to participate in school, we have the dream school success in different social strata." The objective of this work is to list practices developed by social workers with the school management that focuses its activities on the success of the student. The structuring of the work of Social Services took place through the study of socioeconomic families, home visits, individual and group care and monitoring frequency. The contribution of social work at EMABEM is evident in the coordinated actions the school management. The interventions by social services to subsidize qualitative solutions in the teaching and learning in the integration of the student. The social worker helps with the standardization of practices articulate the networks of services in Uberaba, confirming the positive impact on access and participation of families in the construction of a Citizen School.

KEYWORDS: Social worker. Family. Student.

\section{REFERÊNCIAS}

ALMEIDA, N. L. T. de. O serviço social na educação. Revista Inscrita, Brasília, n.6, p.19-24, jul. 2000.

CHIZZOTTI, A. Pesquisa qualitativa em ciências humanas e sociais. 2.ed.

Petrópolis: Vozes, 2008.

GADOTTI, M.; GUTIERREZ, F. Educação comunitária e economia solidária. 4.ed. São Paulo: Cortez, 2005.

GOMES, J. Socialização primária: tarefa familiar? Caderno de Pesquisa, São Paulo, n.91, p.54-61, 1994.

IAMAMOTO, M. V.; CARVALHO, R. de. Relações sociais e serviço social no Brasil: esboço de uma interpretação histórico-metodológico. 25.ed. São Paulo: Cortez, 2008.

NICOLAU, M. C. C. Formação e fazer profissional do assistente social: trabalho e representações sociais. São Paulo: Cortez, 2004. (Serviço Social e Sociedade, n. 79).

SOUZA, P. N. P. de; SILVA, E. B. da. Como entender a aplicar a nova LDB. São Paulo: Pioneira Thomson Learning, 2002.

SZYMANSKI, H. A relação família/escola: desafios e perspectivas. Brasília: Plano, 2003. 